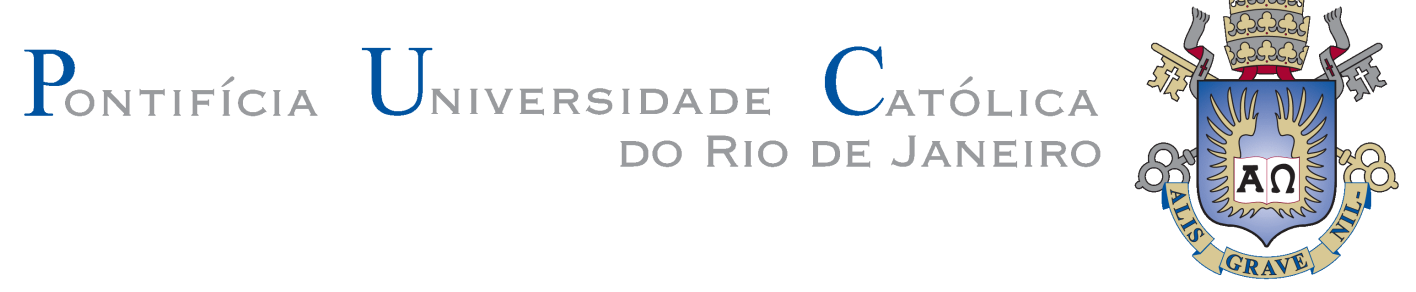

Luciana Villela de Moraes Sarmento

\title{
Ticket to Ride
}

\author{
As tensões entre consumo e contracultura \\ nas letras de música dos Beatles
}

\section{Dissertação de Mestrado}

Dissertação de mestrado apresentada ao Programa de Pós-Graduação em Comunicação Social da PUCRio como requisito parcial para obtenção do título de mestre em Comunicação Social.

Orientador: Prof. Dr. Everardo Rocha

Rio de Janeiro

Fevereiro de 2006 


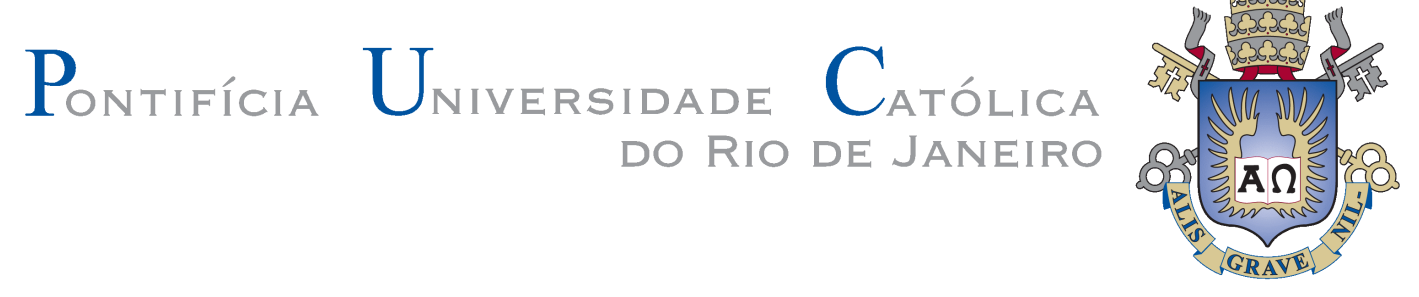

Luciana Villela de Moraes Sarmento

Ticket to Ride

As tensões entre consumo e contracultura nas letras de música dos Beatles

Dissertação de mestrado apresentada ao Programa de Pós-Graduação em Comunicação Social da PUC-Rio como requisito parcial para obtenção do título de mestre em Comunicação Social.

Prof. Everardo P. Guimarães Rocha Orientador

Departamento de Comunicação Social - PUC-Rio

Profa. Maria Cristina Ribas

Departamento de Letras - PUC-Rio

Prof. João Freire Filho Departamento de Comunicação Social - UFRJ

Prof. João Pontes Nogueira Vice-Decano de Pós-Graduação do CCS - PUC-Rio

Rio de Janeiro, 21 de Fevereiro de 2006 
Todos os direitos reservados. É proibida a reprodução total ou parcial do trabalho sem autorização da universidade, do autor e do orientador.

\section{Luciana Villela de Moraes Sarmento}

Graduou-se em Comunicação Social com habilitação em Jornalismo em dezembro de 2001 pela Pontifícia Universidade Católica do Rio de Janeiro. Dedica-se atualmente a pesquisas no campo da música popular e sua relevância acadêmica na área de Comunicação Social.

Ficha Catalográfica

Sarmento, Luciana Villela de Moraes

Ticket to Ride : as tensões entre consumo e contracultura nas letras de música dos Beatles / Luciana Villela de Moraes Sarmento ; orientador: Everardo Rocha. - Rio de Janeiro : PUC, Departamento de Comunicação Social, 2006.

145 f. ; $30 \mathrm{~cm}$

Dissertação (mestrado) - Pontifícia Universidade Católica do Rio de Janeiro, Departamento de Comunicação Social.

Inclui bibliografia.

1. Comunicação Social - Teses. 2. Música popular. 3. Beatles. 4. Rock and Roll. 5. Contracultura. 6. Cultura de massa. 7. Consumo. I. Rocha, Everardo. II. Pontifícia Universidade Católica do Rio de Janeiro. Departamento de Comunicação Social. III. Título.

CDD: 302.23 
Para meus pais, Rosane e Milton, pelo apoio de sempre nas horas mais difíceis. Para meus irmãos, Ricardo, Adriana e Cristiana pela minha criação espiritual e musical. Para meu namorado Andrei, "por todo amor que houver nessa vida" 


\section{Agradecimentos}

Ao meu orientador, Everardo Rocha, pela sapiência.

À CAPES, pela bolsa concedida, que permitiu-me dedicação exclusiva à vida acadêmica, o que foi de importância vital para o resultado final desta dissertação.

Aos professores do mestrado, em especial à Vera Figueiredo, Fernando Resende e Renato Cordeiro Gomes da PUC-Rio, pelas experiências compartilhadas e multiplicadas.

À secretária Marise, pela paciência, carinho e incentivo.

À professora Gisela Castro, pelas experiências compartilhadas e pelo incentivo.

À Cecília, pelo amadurecimento.

Ao meu irmão Ricardo e ao meu cunhado Ricardo, por me guiarem textos afora.

À minha tia Angela e à Catarina, pela hospitalidade e acolhimento.

Ao meu primo-irmão Luiz Eduardo, pelas viagens musicais e beatlenianas.

A toda minha família, especialmente meus avós e meus pais, por me ensinarem o sentido da vida.

Ao meu namorado Andrei, por ter aparecido "bem devagar" na hora certa, no lugar certo e estar sempre do meu lado.

Aos meus amigos, fiéis companheiros de longas jornadas, que, mesmo quando estão longe, estão perto. 


\section{Resumo}

SARMENTO, Luciana. Ticket to ride: as tensões entre contracultura e consumo nas letras dos Beatles. Rio de Janeiro, 2006. 145p. Dissertação de Mestrado - Departamento de Comunicação Social, Pontifícia Universidade Católica do Rio de Janeiro.

A contracultura foi um movimento impulsionado pela juventude da década de 1960 que se chocou com a sociedade capitalista e ia contra os seus princípios. Entretanto, para que este movimento de contracultura pudesse se desenvolver, ele necessitava da cultura de massa - que pertence à sociedade capitalista - para se desenvolver e espalhar sua mensagem pelo mundo. São essas tensões entre consumo e contracultura que são detalhadas nesta dissertação, a partir das letras das músicas dos Beatles (grupo musical que foi um dos maiores ícones da contracultura) que retratam, de alguma forma, o universo do consumo.

\section{Palavras-chave}

Música popular; Beatles; Rock and roll; Contracultura; Cultura de massa; Consumo. 


\section{Abstract}

SARMENTO, Luciana. Ticket to ride: the tensions between the counterculture movement and consumption in Beatles' lyrics. Rio de Janeiro, 2006. 145p. MSc. Dissertation - Departamento de Comunicação Social, Pontifícia Universidade Católica do Rio de Janeiro.

The counterculture was a movement impulsed by the young people in the 1960 's decade that ran into the capitalist society and it's principals. However, for this movement to work, it needed the mass culture - that belongs to the capitalist society - to spread it's message around the world. These tensions between the counterculture movement and consumption are detailed on this dissertation, inspired on the Beatles' lyrics (a rock group that was one of the most popular icons of the countercultere movement) that shows, in some way, the consumption's universe.

\section{Key-words}

Popular music; Beatles; Rock and roll; Counterculture; Mass culture; Consumption. 


\section{Sumário}

1 Introdução

2 Cultura de massa

3 A Contracultura 30

3.1. Antecedentes 30

3.2. O movimento 36

3.3. Trilha sonora 44

4 The Beatles - mito, produto e discurso 55

4.1. Beatles for sale $\quad 55$

4.2. Discurso 80

4.2.1 - Vida cotidiana - A day in the life 84

4.2.2 - Produtos midiáticos - Roll Over Beethoven 89

4.2.3 - Trabalho e profissões - A hard day's night 96

4.2.4 - Contracultura - Piggies 104

4.2.5 - Bens materiais e dinheiro - That's what I want 106

5 Considerações finais e perspectivas futuras 117

6 Referências bibliográficas $\quad 120$

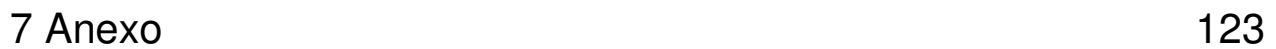


And in the end, the love you take is equal to the love you make.

John Lennon e Paul McCartney 